\title{
Saúde, Espiritualidade e Psicologia: o acolher como um ato de fé e ciência
}

\author{
Health, spirituality and psychology: welcoming as an act of faith and science
}

Salud, espiritualidad y psicología: la bienvenida como acto de fe y ciencia

\section{Michelle Steiner dos Santos ${ }^{1 *}$}

Como citar esse artigo. dos Santos, MS. Saúde, Espiritualidade e Psicologia: o acolher como um ato de fé e ciência. Revista Pró-UniverSUS. 2021 Jan./Jun.; 12 (1): $80-85$.

\section{Resumo}

Este trabalho apresenta para um público geral algumas das concepções de ciência defendidas na modernidade refletindo como estas impactam no estabelecimento de ações voltadas a comunidade nas Instituições de Ensino Superior, sobretudo as que trazem no seu bojo constitutivo inserções sociais focadas no cuidado em saúde e sua relação com a espiritualidade. Tem-se como objetivo deste artigo informar, por meio de relato de experiência, algumas das intervenções extensionistas do Programa de Ações Integradas pela Vida (PÃIM) vinculado ao Departamento de Psicologia da Universidade Federal do Ceará e seus desafios de fazer ciência a luz dos estudos sobre espiritualidade, religiosidade, e sua busca por conectar as Práticas Clínicas em Psicologia as Práticas Integrativas e Complementares em Saúde (PICS) e, portanto, o saber científico aos saberes populares. Através do Acolhimento Psicológico e Plantão de PICS observou-se a possibilidade de se inferir diretamente sobre algumas das questões existenciais fundantes do psiquismo e entre elas: a "fome" e o "amor". É a fome e o amor que geram movimento, e é sobre estas categorias que se organizou no Plantão um fluxo de atendimento com base no acolhimento solidário que integrava intervenções reconhecidas pela sociedade as práticas tradicionais, unindo saúde, educação e espiritualidade. Conclui-se que para muitas das pessoas acolhidas pelo Programa, esta foi a primeira experiência integrada de práticas que lhes ajudou a reconhecer o novo e inimaginável, ou seja, uma ampliação da consciência dos problemas vividos, a percepção da fé nas próprias habilidades e a crença positiva da relação entre Psicologia, PICS e espiritualidade.

Palavras-chave: Acolhimento; Ciência; PICS; Espiritualidade; Psicologia; PÃIM.

\begin{abstract}
This work presents to the general public some of the main conceptions of science defended in modern times, reflecting how these impact on the establishment of actions aimed at the community in Higher Education Institutions, especially those that bring in their constitutive core social inserts focused on health care and its relationship with spirituality. The objective of this article is to present, through an experience report, the extension interventions of the Integrated Actions for Life Program (PÃIM) linked to the Department of Psychology at the Federal University of Ceará and its challenges of making science in the light of studies on spirituality, religiosity, and its search for connecting Clinical Practices in Psychology to Integrative and Complementary Practices in Health (PICS) and, therefore, scientific knowledge to popular knowledge. Through the Reception Service and PICS, the possibility of directly inferring about some of the founding existential issues of the psyche was observed and among them: "hunger" and "love". It is hunger and love that generate movement, and it is on these categories that a service flow was organized at the Service based on solidarity that integrated interventions recognized by society with traditional practices, uniting health, education and spirituality. It is concluded that for many of the people welcomed by the Program, this was the first integrated experience of practices that helped them to recognize the new and unimaginable, that is, an increase in the awareness of the problems experienced, the perception of faith in their own abilities and belief positive relationship between Psychology, PICS and spirituality.
\end{abstract}

Keywords: Reception; Science; PICS; Spirituality; Psychology; PÃIM.

Afiliação dos autores:

${ }^{1 *}$ Psicóloga. Pós Doutora em Engenharia do Conhecimento (UFSC). Professora Associada Universidade Federal do Ceará, Fortaleza, Ceará, Brasil. ORCID: https://orcid.org/0000$0002-6068-4382$

Artigo Premiado no I Congresso Interinstitucional de Espiritualidade em Saúde

* Email de correspondencia: michellesteiner@ufc.br 


\section{Resumen}

Este trabajo presenta al público en general algunas de las principales concepciones de la ciencia defendidas en la actualidad, reflejando cómo estas impactan en el establecimiento de acciones dirigidas a la comunidad en las Instituciones de Educación Superior, especialmente aquellas que traen en su núcleo constitutivo insertos sociales enfocados en la atención de la salud y relación con la espiritualidad. El objetivo de este artículo es presentar, a través de un relato de experiencia, las intervenciones de extensión del Programa Acciones Integradas para la Vida (PÃIM) vinculado al Departamento de Psicología de la Universidad Federal de Ceará y sus desafíos de hacer ciencia a la luz de estudios sobre espiritualidad, religiosidad y su búsqueda de conectar las Prácticas Clínicas en Psicología con las Prácticas Integrativas y Complementarias en Salud (PICS) y, por tanto, el conocimiento científico con el conocimiento popular. A través del Servicio de Recepción y PICS se observó la posibilidad de inferir directamente sobre algunos de los temas existenciales fundacionales de la psique y entre ellos: "hambre" y "amor". Es el hambre y el amor los que generan movimiento, y es en estas categorías que se organizó un flujo de servicios en el Servicio basado en la solidaridad que integró intervenciones reconocidas por la sociedad con prácticas tradicionales, uniendo salud, educación y espiritualidad. Se concluye que para muchas de las personas acogidas por el Programa, esta fue la primera experiencia integrada de prácticas que les ayudó a reconocer lo nuevo e inimaginable, es decir, un aumento en la conciencia de los problemas vividos, la percepción de fe en sus propias habilidades y creencias. relación positiva entre Psicología, PICS y espiritualidad.

Palabras clave: Recepción; Ciencias; PICS; Espiritualidad; Psicología; PÃIM.

\section{Introdução}

Existe algo que causa inquietação e incomodo quando se analisa o mundo acadêmico: a distância entre o que se define como conhecimento científico e o conhecimento popular. O afastamento da dimensão espiritual e do saber oriundo das doutrinas religiosas e espiritualistas do ambiente universitário. $\mathrm{O}$ uso pejorativo de palavras como: macumba, feitiçaria, charlatanismo, curandeirismo sem apropriação, sem reflexão, sem contextualização, sem ciência, ou seja, sem um conhecimento atento e aprofundado do tema.

A ciência ou as ciências são sistema de crenças que se destacam pelo rigor metodológico, pelo alto grau de indução, oriundas de observações sistematizadas e baseadas numa suposta neutralidade, tais teorias, técnicas, produtos e métodos quando considerados científicos tendem a contar com aprovação geral da sociedade $^{1 .}$

"O cientista contemporâneo sabe bem que nada há de definitivo e indiscutível que tenha sido assentado por homens"2. Quem desenvolve pesquisa nas ditas Ciências Humanas conseguem identificar que antes da matéria, objetiva e palpável, traduzida em rigor e método há o ato imaterial, assentado no instinto, num saber prático, muitas vezes oralizado através de narrativas populares, e entre ambos um hiato de transição que não é imediato ${ }^{3}$. "Os pensamentos dormem longo tempo; quase imediatamente, depois a humanidade sente que se incorporou a si mesma em instituições"4. Falar da relação da espiritualidade com a ciência, entre saúde e práticas integrativas na academia é discutir sobre tessituras e rupturas que se conectam e desconectam em metodologias e definições permeadas pela observação apurada, crenças e fé.

A fé ou o ceticismo ${ }^{5}$, a existência de crenças misticas ou a ausência destas fazem parte do humano, qual o sentido das mesmas se manterem a margem dos estudos, reflexões e discussões que são tecidas nas intuições de ensino superior, principalmente nas graduações em Saúde e Ciências Humanas? É possível uma discussão aprofundada e menos superficial ou uma intervenção mais integrada da sociedade, do humano e dos aspectos constitutivos: educação e saúde, sem a presença destes temas na formação profissional? O que as religiões e as ciências como a Psicologia, Enfermagem, Medicina, Ciências Sociais, Antropologia, etc. têm a discorrer sobre as dimensões que atuam como formas de "religare", laços que unem a humanidade e se conectam com o "invisível"? Ao falar de espiritualidade e o amor, por diferentes vieses, quais semelhanças e distanciamentos é possível estabelecer? E a pergunta cujas ciências não têm resposta: existe um laço que liga "tudo a todos"? Caso positivo, qual a natureza do vínculo?

"É preciso considerar que, sobre a Terra, não se vê a humanidade, mas apenas uma pequena fração dela" "Esta reflexão é primordial, pois ao se falar da espiritualidade, ciência e Psicologia, estar-se-á remetendo a um pequeno fragmento dos afetos humanos: o amor terreno em suas vicissitudes e encontros.

Entende-se a espiritualidade como uma prática fundamentada no amor, na capacidade genuína de se colocar no lugar do outro, de ser solidário e desenvolver relações conscientes e recíprocas de bem-estar, em conjunto com os semelhantes e com mundo em que se vive.

De natureza multifacetada, o Amor se configura como uma presença universal de um poder de ligação "entre" pessoas, um objeto que reflete a partir do Outro, o $\mathrm{Eu}^{8,9}$. Os significados atribuídos ao amor e seus enviesamentos indicam as buscas, as questões existenciais presentes na relação do "eu" com o "tu"10 e a configuração existente a partir da junção de ambos num "nós" e os contextos de transformação singular e coletivos que insurgem dos elos e fraturas.

Neste artigo tem-se como objetivo relatar as experiências de extensão do Programa de Ações 
Integradas pela Vida(PÃIM) vinculado ao Departamento de Psicologia da Universidade Federal do Ceará e seus desafios de fazer ciência a luz dos estudos sobre espiritualidade, religiosidade, na busca de interligar as Práticas Clínicas em Psicologia as Práticas Integrativas e Complementares em Saúde (PICS) com os saberes populares.

A relevância do trabalho está justamente na relação que se procura estabelecer entre os diferentes saberes e resistências, tendo em vista as dissonâncias entre as práticas cotidianas e necessidades da população que nem sempre coadunam com o que se estuda nas Instituições de Ensino Superior (IES) e as normatizações e orientações trazidas pelos Conselhos Profissionais

\section{Metodologia}

Metodologicamente o relato apresentado se constitui num registro de experiência baseado na descrição reflexiva de um programa de extensão formado a partir de projetos isolados durante o período de (2010-2014) e formalizado como Programa junto a Pró-Reitoria de Extensão da Universidade Federal do Ceará (2015), vigente atualmente.

Com a missão de desenvolver ações permanentes de promoção da vida com base na integração e respeito as diferenças humanas. O PÃIM existe para ajudar e apoiar as pessoas a melhorarem a qualidade de suas vidas e ampliarem a consciência sobre si mesmas e o mundo que as rodeia por meio de ações ensino, pesquisa e intervenção em Psicologia e PICS, que tenham como elo a integração e a luta pela conservação da vida humana e dos Direitos Fundamentais do Homem, nos seus múltiplos aspectos: físico, psíquico, espiritual, social e cultural, a partir de três pilares: saúde, educação e espiritualidade.

Define-se por saúde a busca de integração e de adaptação entre o ser e o contexto em que vive, contemplando seus limites e possibilidades, o despertar da capacidade de desenvolver estratégias efetivas, afetivas e criativas de existência, bem como a ampliação da consciência sobre si mesmo, o ambiente e o planeta. Não é ausência de doença ou o perfeito bem-estar físico, mental, social e espiritual.

A dimensão espiritual para o Programa está vinculada à compreensão do ser material, em suas experiências sociais, familiares e subjetivas; e imaterial, no desejo íntimo de ligação com o Sagrado. As várias possibilidades de transcendência, representadas pelas diversas expressões religiosas, espirituais e espiritualistas são contempladas, por entendermos que estas se remetem ao momento experimentado pelo ser, na sua busca de entendimento do sentido da vida e de seu destino.

Para o PÃIM permeando as ações em saúde e espiritualidade está a educação, que é resultado de uma articulação social que se constrói e reconstrói, como num jogo dinâmico, em espaços formais e informais de aprendizagem e sociabilidade. Relações familiares, comunitárias, sociais, religiosas e espirituais são peças fundamentais de uma engrenagem denominada cultura, marca original de um povo, que forja pessoas nas suas individualidades e os grupos na qual estas se vinculam.

Embora seja um Programa voltado a comunidade em geral, dá-se preferência ao atendimento das pessoas em situação de vulnerabilidade social e risco.

\section{Resultados e Discussão}

\section{Da ciência a espiritualidade, o acolher e o amar como elos possíveis entre a Psicologia e as Práticas Integrativas e Complementares em Saúde (PICS)}

Pioneiro na implantação do Plantão em Práticas Integrativas e Complementares em Saúde (PICS) associado ao Acolhimento Psicológico em IES públicas (2018) e como serviço de apoio em saúde mental durante a Pandemia do COVID19. O Plantão em PICS consistiu num fluxo de atendimento de alta intensidade e curta duração, sem tempo delimitado e cujos profissionais estão em sistema de escala para atender as emergências que surjam durante o período de seu turno usando o Acolhimento Psicológico, que é constituído de escuta sensível e aplicação de uma das PICS ofertadas pelos extensionistas, com encaminhamento quando necessário e de acordo com escala de risco e complexidade do caso para a escuta breve através de psicólogos voluntários ou para a rede pública de saúde mental do município.

OPrograma se destaca pela atenção e saúde mental a população em geral, a formação plural, ampliada e integrada dos alunos de Psicologia envolvidos. Realiza ações de prevenção a agravos psíquicos por meio de intervenções em PICS e da Psicologia Clínica, junto à comunidade interna (alunos de IES públicas) e externa, e busca estabelecer diálogos com outras ciências como a Pedagogia, Enfermagem, Educação Física e Fisioterapia além de estruturar sua metodologia de trabalho a partir de estudos sobre diferentes racionalidades médicas. Em especial, os sistemas médicos complexos e os recursos terapêuticos, também denominados de Medicinas Tradicionais e Complementares/Alternativas (MT/ MCA) e sua correlação com a filosofia e religião ${ }^{11}$.

A eficácia destes sistemas tem sido atestada através de evidências científicas produzidas pela Rede de Medicinas Tradicionais, Complementares e Integrativas (MTCI)Américas, pelo Consórcio Acadêmico Brasileiro de Saúde Integrativa (Cabsin) e pelo Centro LatinoAmericano e do Caribe de Informação em Ciências da 
Saúde (Bireme/Opas/OMS)", bem como indicadas nas Estratégias da OMS sobre Medicina Tradicional (2014$2023)^{12,13}$.

O Brasil é referência ao normatizar mais de 29 práticas, predominantemente desenvolvidas na atenção básica e voltadas a estimular os mecanismos naturais de prevenção e recuperação da saúde por meio de tecnologias eficazes e seguras, com ênfase na escuta acolhedora, no desenvolvimento do vínculo terapêutico e na integração do ser humano com o meio ambiente $\mathrm{e}$ a sociedade ${ }^{14,15,1617}$.

Após cinco anos ininterruptos de atuação observamos alguns aspectos que se destacaram nos atendimentos do Plantão: o Acolhimento como abordagem diferencial, na recepção, identificação de demanda e encaminhamento do usuário ou como atitude do profissional que presta serviço. Esta etapa inicial do fluxo se mostrou essencial frente as inúmeras e diversificadas queixas de adoecimento psíquico, das quais a disfuncionalidade amorosa apareceu em maior número apresentando-se como uma síndrome característica da contemporaneidade.

Acolher é a ação de oferecer ou obter refúgio ou proteção; abrigar(-se), amparar(-se) ${ }^{18}$. $\mathrm{O}$ acolhimento é uma ação de agentes semelhantes em papéis diversos. O que acolhe tem o conhecimento técnico em Psicologia que permite a formação de um campo protetivo e potencializador; o que é acolhido busca conforto, atenção, "presença". A natureza desta relação é transferencial respaldada por uma ética do amor, que tem como base o contato genúno, a reciprocidade nas trocas e a empatia, congruentes ao contexto experiencial do psicólogo e seu analisante.

Observou-se que a impossibilidade de uma transferência recíproca, é que impede a pessoa de enxergar os rostos que intimam sua existência, e na tentativa de fuga deste espelhamento, resiste-se a si próprio. $\mathrm{O}$ encontro com o Outro é que permite a real vivência da humanidade. É a face do irmão que "pedeme e ordena-me" 19 , aquela que me intima o olhar para dentro, que representa a categoria fundante e estruturante da subjetividade: "de ser e de viver". Quando do "risco absoluto de deixar de ser, de existir, de not to be, o que se tem? A declaração do amor ${ }^{20}$. Em última instância o acolhimento é um ato de fé no humano, uma ode ao amor, um espaço de expressão dos afetos.

Como sujeitos de falta, é a fome e o amor que impulsionam os homens e estes movem o mundo ${ }^{21}$. Assim, percebe-se que o que leva as pessoas a buscarem um plantão híbrido que agrega atendimentos em Psicologia e PICS é exatamente as faltas, cujas origens são representadas por um ou mais desejos que se estruturam mediante a percepção de que algo está escasso, confuso e falho.

O especto inusual da Pandemia que tornou a Ação presencial remota, e enfatizou a importância do
Acolhimento permitiu verificar que esta "falta" presente nos discursos enunciava inúmeras outras perdas e suas consequências: luto pelos que morreram pelo vírus, pesar pela não execução dos rituais de morte dada a natureza contagiosa da doença, a ampliação dos casos de violência doméstica, o aumento do percentual de ingestão de drogas lícitas e ilícitas, as crises de ansiedade e de tristeza vinculadas ao distanciamento social e pela restrição da liberdade de ir e vir, da diminuição dos contatos, sobretudo, os de natureza física, dos silêncios cada vez maiores a medida que os meses se arrastavam, e os efeitos econômicas que incidiram sobre a empregabilidade, ampliaram a pobreza e tornaram um contingente de pessoas mais vulneráveis socialmente.

Para estas situações o acolhimento remoto e gratuito ofertado pelo PÃIM diminuiu a sensação da solitude, possibilitou pela afirmação do profissional ao sujeito reduzir os medos e entre eles os referentes a natureza das próprias intervenções, emoção secundária negativa, muitas vezes edificada no desconhecimento e falta de informação sobre as psicoterapias e as próprias PICS.

Foram depoimentos dos usuários durante os atendimentos realizados entre abril a setembro de 2020 que a Ação Emergencial Remota em Tempos de COVID possibilitou: ampliar a percepção da importância do acompanhamento psicológico, que esta permitiu o desabafar, o acalmar, o esclarecer, o aprendizado de técnicas que facilitaram o enfrentamento do cotidiano (recursos como os da ampliação da consciência sobre a respiração, de meditação, de automassagem, etc.), o sentir-se confortável com o ambiente e com a própria escuta que embora não-presencial foi identificada pelo usuário como capaz de acalmar, amparar e ressignificar o momento vivido.

Para muitas das pessoas acolhidas pelo Programa o "Plantão de PICS e acolhimento psicológico" foi a primeira experiência relacionando as práticas convencionais e tradicionais em saúde e que, segundo os relatos, lhes ajudaram a reconhecer e experienciar o novo e inimaginável, ou seja, permitiram uma ampliação da consciência dos problemas vividos, a percepção da fé nas próprias habilidades e a crença positiva da relação entre Psicologia e PICS.

Vivenciou-se durante este período uma dissonância entre o vivido no Programa e o que é posto pelos normativos do Conselho Federal de Psicologia (CFP) Para o CFP as PICS são um "conjunto de métodos e técnicas terapêuticas", não reconhecidas. Esta forma de pensar nega a categoria dos psicólogos o direito destes de fazerem o uso dessas técnicas no exercício da Psicologia, exceto em caráter experimental e gratuito, orientação normativa que vai na contramão das avaliações tecidas pelos usuários do PÃIM.

Esta postura do CFP leva suscitar a reflexão do quão tênue pode ser a linha que separa a proteção de 
uma categoria profissional e dos cidadãos e as ideologias de grupo, e que este limiar pode "se aproximar mais ou menos do preconceito e/ou descaso pelo tema, assim como, pode indicar certo excesso tutelar sobre o exercício criativo da profissão"22.

Assim percebe-se que não é necessariamente a ciência ou o que se mostra útil a sociedade o que de fato legitima o que pode ou não ser ofertado como prática científica ou não em saúde.

Semelhante dilema é encontrado quando se usa a ciência, a despeito do que a configura, como forma de controle social na produção de conhecimentos e procedimentos considerados por determinados segmentos como válidos ou inválidos. "A ciência é uma valiosa publicidade para adesão de protocolos assistenciais rentáveis" ${ }^{\prime 23}$.

Estudos apontam ${ }^{23,24,25}$ sobre eficácia e efetividade das PICS como recursos alternativos a promoção da saúde e prevenção de agravos, sobretudo na atenção básica, dado ao baixo custo, alto alcance da população e o "potencial de desmedicalização" 2 . O que coaduna com os resultados obtidos através da avaliação do Programa pelos usuários do PÃIM.

O interessante nas discussões de negação ou de confirmação do uso das PICS e da espiritualidade é que elas indicam que o modelo biomédico de atenção à saúde ocidental necessita ampliar seu olhar para a diversidade e complexidade dos problemas de saúde, convoca as IES, em sua finalidade formativa, a integrar, no que se refere a compreensão de saúde, os conhecimentos biológicos, psicológicos, sociais, culturais e espirituais nas definições do que seja saúde e doença. Assim como demanda aos Conselhos Profissionais que estes respeitem a autonomia da IES e realizem uma autoreflexão sobre o uso de ideologias na orientação dos profissionais a ele vinculados.

Por último e não menos importante, pesquisas atuais indicam que a religiosidade $\mathrm{e}$ as práticas espiritualistas, presentes em várias PICS, dão sentido à vida, diante do sofrimento, ao criar uma rede social de apoio e tem complementado e não substituindo as práticas médicas oficiais ${ }^{22}$.

\section{Considerações Finais}

A dificuldade em se conceituar o que é científico ou não, de estabelecer aproximações e distanciamentos entre os conhecimentos oriundos de filosofias e medicinas tradicionais, como a chinesa, e as racionalidades ocidentais ditas científicas demonstram que a diversidade de referências e suas procedências podem levar ao desacordo entre as definições, assim como a suposta cisão e a complexidade dos temas discutidos neste artigo indicam que toda teorização é incompleta em si já quem provém de um recorte epistemológico e/ou experiencial humano.

Como foi indicado as PICS são consideradas práticas emergentes que não necessariamente vieram da Psicologia, mas podemapresentarbons resultadosquando aplicadas em consonância as técnicas e intervenções psicológicas. O PÃIM se constitui como um locus, um observatório através do qual é possível vislumbrar os dilemas e as necessidades reais de ampliação do diálogo entre a ciência e as práticas tradicionais e o elos de integração: a educação e a espiritualidade.

Finaliza-se esta escrita ensejando uma atitude de prudência e de curiosidade, uma atenção especial e aprofundada sobre os temas trazidos. Salienta-se a necessária reflexão quando da junção de conhecimentos oriundos de fontes diversas e que permeiam as práticas ortodoxas e as tradicionais em saúde sobre a importância da dimensão espiritual na formação do ensino superior.

\section{Referências}

1. Chibeni SS, O que é ciência? [Internet].2020 [cited 2020 out 15]. Available from: https://www.unicamp.br/ chibeni/textosdidaticos/ciencia.pdf

2. Freire-Maia N. A ciência por dentro. 5. ed. Rio de Janeiro: Vozes; 1998.

3. Whitehead AN. A ciência e o mundo moderno. São Paulo: Brasiliense; 1946

4. Francelin MM, Ciência, senso comum e revoluções científicas: ressonâncias e paradoxos Ci. Inf., Brasília, 2004 set./dez;33(3):26-34.

5. Loque FF, Ceticismo e religião no início da modernidade. São Paulo: Loyola, 2012.

6. Jung CG, Psicologia e Religião. Petrópolis: Vozes; 1978.

7. Kardec A, O evangelho segundo o espiritismo. São Paulo: IDE; 2009.

8. Lévinas E. Ética e Infinito. Lisboa: Edições 70; 1982, p.38.

9. Quinet A. I can get, yes, satisfaction. In: _. O amor e suas letras. Rio de Janeiro: 7 Letras; 2011, p. 28-32

10. Buber M, Eu e Tu. São Paulo: Centauro; 2001.

11. Nascimento MC, Barros NF, Nogueira MI, Luz MT. A categoria racionalidade médica e uma nova epistemologia em saúde. Ciênc. saúde coletiva [Internet]. 2013.

12. WHO, World Health Organization (WHO). WHO traditional medicine strategy: 2014-2023. Geneva: WHO Press; 2013. [cited 2020 mar 15]. Available from: https://www.who.int/medicines/publications/traditional/ trm strategy 14 23/en

13. Brasil, Ministério da Saúde (BR). Departamento de Atenção Básica (DAB/MS) [publicação online]; 2020 [cited 2020 out 01]. Available from: http://dab.saude.gov.br/portaldab/noticias.php? conteudo=_\&cod=3152.

14. Brasil, Ministério da Saúde (BR). Portaria $N^{\circ} 971$ de 03 de maio de 2006. Aprova a Política Nacional de Práticas Integrativas e Complementares (PNPIC) no Sistema Único de Saúde. Brasília (DF): Ministério da Saúde; 2006. [cited 2020 out 01]]. Available from: http://bvsms.saude.gov.br/bvs/ saudelegis/gm/2006/prt0971 03 05 2006.html.

15. Brasil, Ministério da Saúde (BR). Portaria No 849 de 27 de março de 2017. Inclui a Arteterapia, Ayurveda, Biodança, Dança Circular, Meditação, Musicoterapia, Naturopatia, Osteopatia, Quiropraxia, Reflexoterapia, Reiki, Shantala, Terapia Comunitária Integrativa e Yoga à Política Nacional de Práticas Integrativas e Complementares. Brasília (DF): Ministério da Saúde; 2017. [cited 2020 out 01]. Available from: http://bvsms.saude.gov.br/bvs/ saudelegis/gm/2017/prt0849_28_03_2017.html 13 
16. Brasil, Ministério da Saúde (BR). Portaria No 702 de 21 março de 2018. Altera a Portaria de Consolidação no 2/GM/MS, de 28 de setembro de 2017, para incluir novas práticas na Política Nacional de Práticas Integrativas e Complementares - PNPIC. Brasília (DF): Ministério da Saúde; 2018. [cited 2020 out 01$]$ ]. Available from: http://bvsms.saude.gov.br/bvs/saudelegis/ $\mathrm{gm} / 2018 /$ prt0702_22_03_2018.html

17. Brasil, Ministério da Saúde (BR). Informes da Atenção Básica No 53. Práticas Integrativas e Complementares no SUS: ampliação do acesso. Brasília (DF): Ministério da Saúde; 2009. [cited 2020 out 01]]. Available from: http://189.28.128.100/dab/docs/publicacoes/informes/psfinfo53.pdf.

18. Oxford, Dicionário Online de Português, "Acolher". [Internet] 2020. [cited 2020 out 01]]. Available from: Disponível em: https://www.dicio.com. br/oxford/

19. Lévinas E. Ética e Infinito. Lisboa: Edições 70; 1982, p.38.

20. Quinet A. I can get, yes, satisfaction. In: _. O amor e suas letras. Rio de Janeiro: 7 Letras; 2011, p. 28-32

21. Allouch J, O amor Lacan. Rio de Janeiro: Companhia de Freud, 2010.

22. Barreto AF, A psicologia e as práticas integrativas e complementares no SUS. In:Psicologia e Políticas Públicas: práticas inovadoras para o SUS. Maceio: UNIFASF, 2018.

23. Iischkanian PC, Pelicioni, MCF, Challenges of complementary and alternative medicine in the sus aiming to health promotion, Journal of Human Growth and Development, 2012; 22(2): 233-238.

24. Lima KMSV, Silva KL, Tesser CD, Práticas integrativas e complementares e relação com promoção da saúde: experiência de um serviço municipal de saúde. Interface (Botucatu), Botucatu, 2014 June; 18(49): 261-272.

25. Luz, MT, Cultura contemporânea e medicinas alternativas: novos paradigmas em saúde no fim do século XX. Physis: Revista Saúde Coletiva, 1997;7(1):13-43. 